\title{
Experimental and numerical simulation of a storage tank connected to a flat-plate solar collector
}

\author{
A. Álvarez ${ }^{1}$, M. Baz ${ }^{2}$, O. Cabeza ${ }^{3}$ J.L. Ferrín ${ }^{4}$, M.C. Muñiz ${ }^{4}$ and L.M. Varela ${ }^{5}$ \\ ${ }^{1}$ Departamento de Ingeniería Naval y Oceánica. Escuela Politécnica Superior, Universidad de La Coruña, \\ 15403 La Coruña (Spain), email: aalvarez@udc.es \\ ${ }^{2}$ Máster en Energías Renovables y Sostenibilidad Energética, Universidad de Santiago de Compostela, \\ 15782 Santiago de Compostela (Spain), e-mail: marta.baz@,rai.usc.es \\ ${ }^{3}$ Departamento de Física, Universidad de La Coruña \\ 15702 La Coruña (Spain), e-mail: oscabe@udc.es \\ ${ }^{4}$ Departamento de Matemática Aplicada, Universidad de Santiago de Compostela, \\ 15782 Santiago de Compostela (Spain),e-mail: mcarmen.muniz@usc.es, joseluis.ferrin@usc.es \\ ${ }^{5}$ Departamento de Física de la Materia Condensada, Universidad de Santiago de Compostela, \\ 15782 Santiago de Compostela (Spain), e-mail: luismiguel.varela@usc.es
}

\begin{abstract}
In this study, the thermo--hydrodynamic behaviour of the heat transfer fluid in a storage tank connected to a domestic solar collector is investigated. In order to do this, a numerical simulation of the fluid inside the storage tank is performed using Ansys Fluent. The numerical results are then compared with experimental measurements, taken from a new design of a flat-plate solar collector, showing a good agreement.
\end{abstract}

\section{Key words}

Storage tank, sandwich--like solar collector, heat transfer fluid, numerical simulation, turbulence model and experimental measurements.

\section{Introduction}

Thermal energy storage is a key component of a domestic solar hot water collection device which may significantly improve its efficiency (see [1]-[5]). In this investigation, the heating curves of a common storage tank connected to a new design of flat-plate, sandwich-like solar collector with serpentine ducts (see [6]) are experimentally measured in order to be compared to those obtained numerically by modelling the storage tank with a commercial Computational Fluid Dynamics (CFD) code. More precisely, we study the case of sensible heat storage, using a $40 \%$ in volume water-ethylene glycol mixture as a heat transport fluid. The behaviour of this fluid is governed by the continuity, momentum and energy equations complemented with a standard $k-\varepsilon$ turbulence model (see [7]). Besides, the heat transfer fluid is considered as an incompressible and viscous fluid. Nonlinear variations with temperature in the thermal properties are also considered.

\section{Experimental Setup Description}

A sketch of the equipment used for experimental measurements is shown in Figure 1. It has the following components:

1) A prototype flat-plate sandwich-like collector with serpentine configuration which was manuallycrafted in series 1000 aluminium (see [6]). Its $1 \mathrm{~m}^{2}$ absorber plate was anodized with a $25 \mu \mathrm{m}$ matt black Cr film.

2) A commercial collector from Brown Boveri Corporation, hereafter $\mathrm{BBC}$, with parallel configuration and $1.14 \mathrm{~m}^{2}$ of sun exposure area.

3) A commercial collector F3-Heliostar 252 from the Roth Werke Company, henceforth Roth, with parallel configuration and $2.27 \mathrm{~m}^{2}$ of sun exposure area. This collector is an example of those with copper tubes in harp configuration, with a thin copper plate blackened with a tinox recover, ultrasonic melted in the side faced to the sun.

4) Three storage tanks as the one shown in Figure 2, whose dimensions are given in Table I. The tanks were insulated with $30 \mathrm{~mm}$ thick mineral wool insulation layer, acquired from Rockwool and used as received, to minimize energy losses of energy through the walls. 
5) A pump N. 20713 DAB (DAB pumps SPA) with adjustable flow rate ranging from 16 to $291 \mathrm{~min} / 1$.

6) A Crison thermometer with a precision of $0.1^{\circ} \mathrm{C}$.

7) A thermographic camera FLIR i7 with thermal sensitivity / NETD $<0.1^{\circ} \mathrm{C}$, a spectral range between 7.5 and $13 \mu \mathrm{m}$ and temperature range between $0^{\circ} \mathrm{C} \mathrm{y}$ $250^{\circ} \mathrm{C}$.

8) Connectors and pipes between the collector, the pump and the tank.

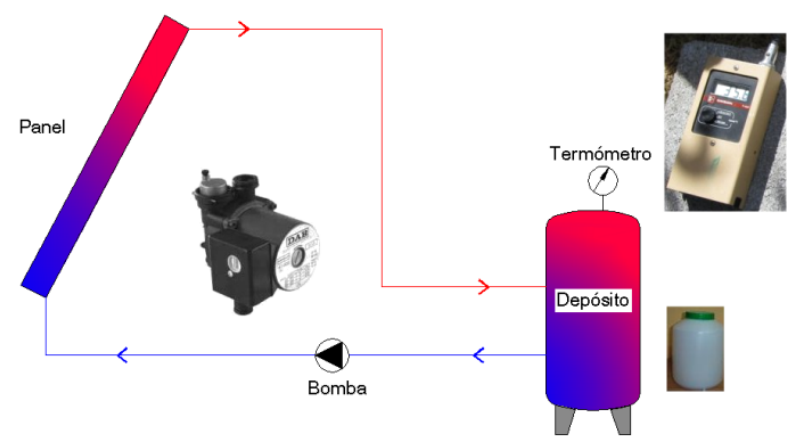

Fig.1: Schematic of the experimental equipment

Table I. - Tank dimensions

\begin{tabular}{|c|c|}
\hline Diameter & $380 \mathrm{~mm}$ \\
Hight & $441 \mathrm{~mm}$ \\
Thickness & $5 \mathrm{~mm}$ \\
Volume & 501 \\
\hline
\end{tabular}

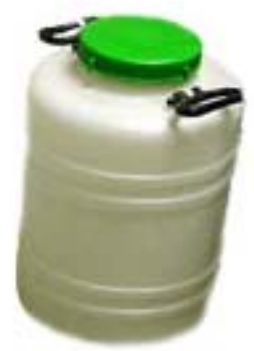

Fig.2: Storage tank

This experimental setup was installed in the geographic location of Villapene, Cospeito (Lugo-Spain). The three collectors were facing south with a collector tilt angle of 350 (see [8]) and connected with three identical tanks provided with the same external insulation. The experiment was performed on September 26, 2010, between 12:40 and 17:30 (GMT+01:00), see Figure 3. Figures 4 and 5 show the values of global irradiation onto $35^{\circ}$ inclined surfaces and the ambient temperature, respectively, for that day; note that the experiment initial time $\mathrm{t}=0$ corresponds to $12: 40 \mathrm{~h}(\mathrm{GMT}+01: 00)$. These values were obtained from data provided by MeteoGalicia, see [9].

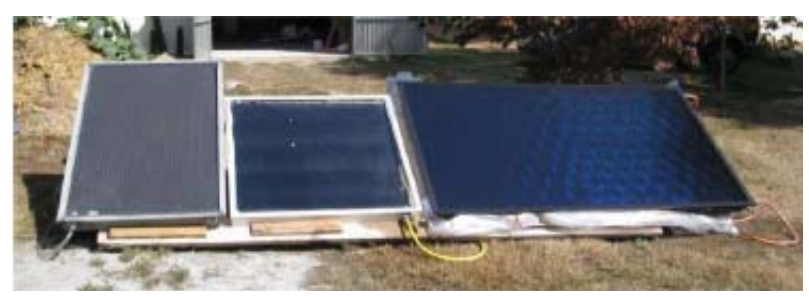

Fig.3: Collectors on September 26, 2010: BBC (left), prototype (middle) and Roth (right).

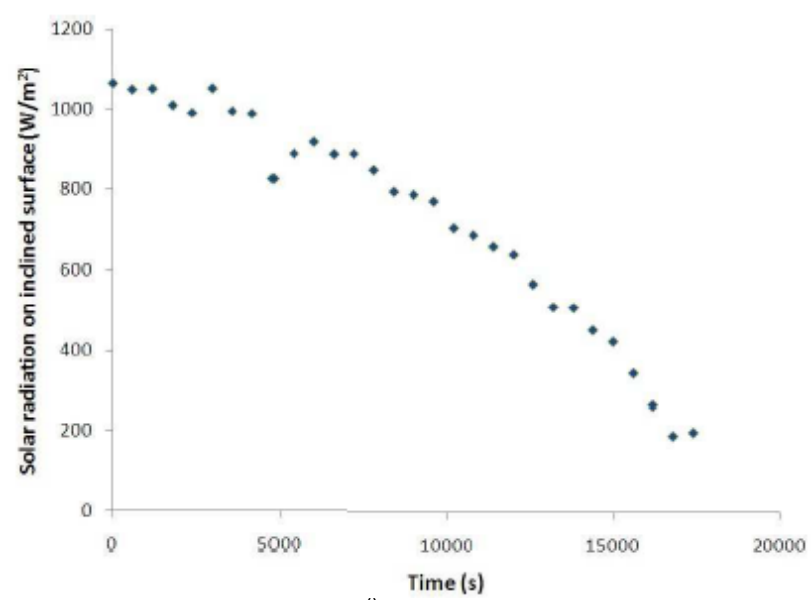

Fig.4: Solar radiation on $35^{\circ}$ inclined surface facing south on the geographic location Castro Ribeiras de Lea (Castro de Rei) on September 26, 2010, (W/m2). Data provided from MeteoGalicia.

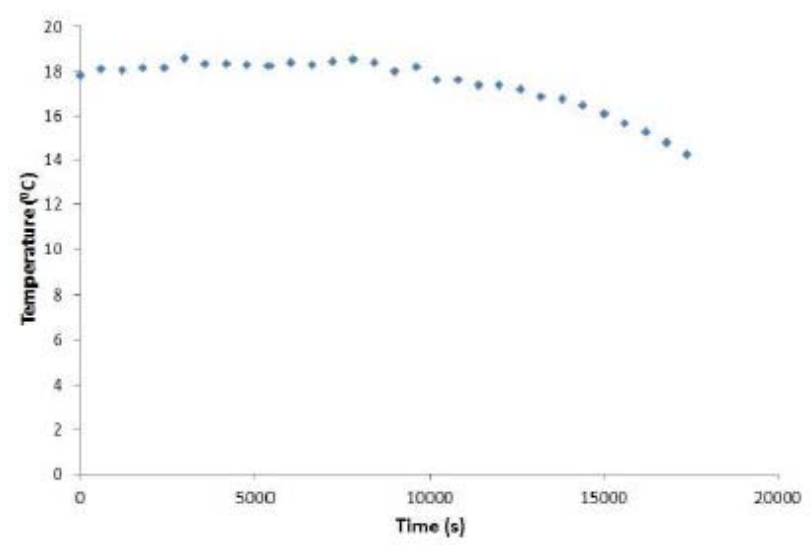

Fig.5: Evolution of ambient temperature with time on the geographic location Castro Ribeiras de Lea (Castro de Rei) on September 26, 2010. Data provided from MeteoGalicia.

\section{The physical problem}

In order to perform a 3D fluid dynamic simulation of the tank, the conservation equations of mass, momentum and energy are taken into account in the domain, $\Omega$, corresponding to the interior of the storage tank minus the inlet and outlet pipes. In Figure 6 two views of the tank geometry can be seen outlining the inlet and outlet ducts. Furthermore, in Figure 7 a radial section of the domain comprising the inlet and outlet ducts is depicted and the nomenclature for the boundaries is shown, $\Gamma_{i}$ being the inlet boundary, $\Gamma_{o}$ the outlet one and $\Gamma_{w}$ the tank walls. 

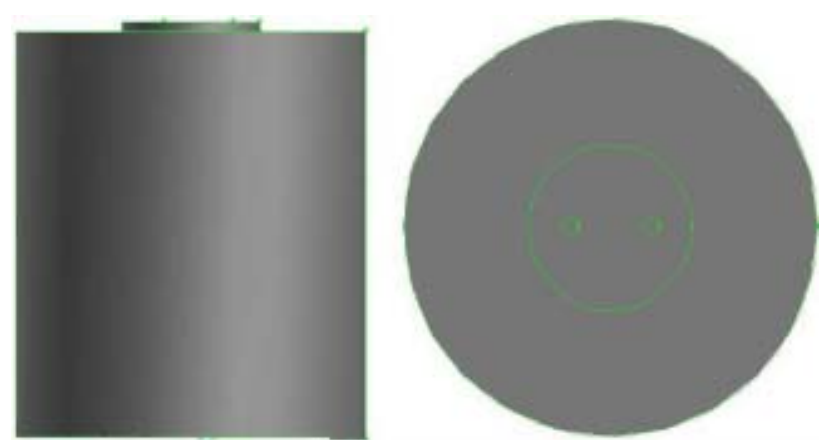

Fig.6: Tank geometry: lateral (left) and top (right) views.

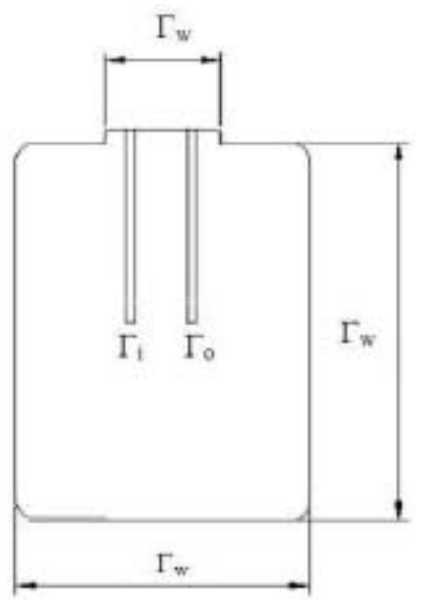

Fig.7: Boundaries

Besides, the partial differential equations numerically solved in the domain $\Omega$ are the following (see [10]):

\subsection{Conservation of mass:}

$$
\frac{\partial \rho}{\partial t}-\nabla \cdot(\rho \vec{v})=0
$$

where $\rho$ is density, $t$ time and $\vec{v}$ velocity vector.

\subsection{Conservation of momentum:}

$$
\frac{\partial}{\partial t}(\rho \vec{v})+\nabla \cdot(\rho \vec{v} \vec{v})=-\nabla p+\nabla \cdot \overline{\bar{\tau}}
$$

where $p$ is the static pressure, and $\overline{\bar{\tau}}$ is the stress tensor, which is defined for a Newtonian fluid as follows:

$$
\overline{\bar{\tau}}=\mu\left[\left(\nabla \vec{v}+\nabla \vec{v}^{T}\right)-\frac{2}{3} \nabla \cdot \vec{v} I\right],
$$

where $\mu$ is the dynamic viscosity. The second term in this expression reflects the effect of the volume expansion, I being the unit matrix.

\subsection{Conservation of energy:}

The equations of this section satisfy the third principle: the energy is conserved.

$$
\frac{\partial}{\partial t}(\rho E)+\nabla \cdot(\vec{v}(\rho E+p))=\nabla \cdot(k \nabla T),
$$

where $k$ is the thermal conductivity. The total energy, denoted by $E$, is given by

$$
E=h-\frac{p}{\rho}+\frac{|\vec{v}|^{2}}{2},
$$

where $h$ is the enthalpy, defined by

$$
h=h^{0}+\int_{T_{\text {ref }}}^{T} C_{p}(\tau) d \tau,
$$

$h^{0}$ being the formation enthalpy at the reference temperature, $T_{\text {ref }}$, and cp the specific heat. Note that the right-hand side of (4) represents the energy transferred by conduction.

Finally, we complete the problem by giving the following boundary and initial conditions:

On the inlet boundary, $\Gamma_{i}$ velocity and temperature are known:

$$
\begin{array}{r}
\vec{v}=\vec{v}_{i} \\
T=T_{i} .
\end{array}
$$

On the outlet boundary $\Gamma_{o}$, a standard free flow outlet condition is considered:

$$
\begin{aligned}
& \overline{\bar{\tau}} \vec{n}-p \vec{n}=0 \\
& \frac{\partial T}{\partial \vec{n}}=0 .
\end{aligned}
$$

And, finally, on the tank walls, $\Gamma_{w}$, a non-slip and a convective boundary conditions for velocity and temperature, respectively, are taken into account:

$$
\begin{gathered}
\vec{v}=0 \\
\frac{\partial T}{\partial \vec{n}}=\alpha\left(T_{a}-T\right) .
\end{gathered}
$$

where $T_{i}$ and $T_{a}$ are time-dependent inlet and ambient temperatures, respectively. Both temperatures depend on time and are fitted through a polynomial of degree three for ambient temperatures and five for inlet temperatures from the experimental data shown in Figures 5 and 8, respectively. The heat transfer coefficient, $\alpha$, in equation (12) is obtained as a thermal conduction-convection network, see [12], being equal to $1.716 \mathrm{~W} / \mathrm{m}^{2} \mathrm{~K}$ on the lateral wall and $1.856 \mathrm{~W} / \mathrm{m}^{2} \mathrm{~K}$ on the top wall.

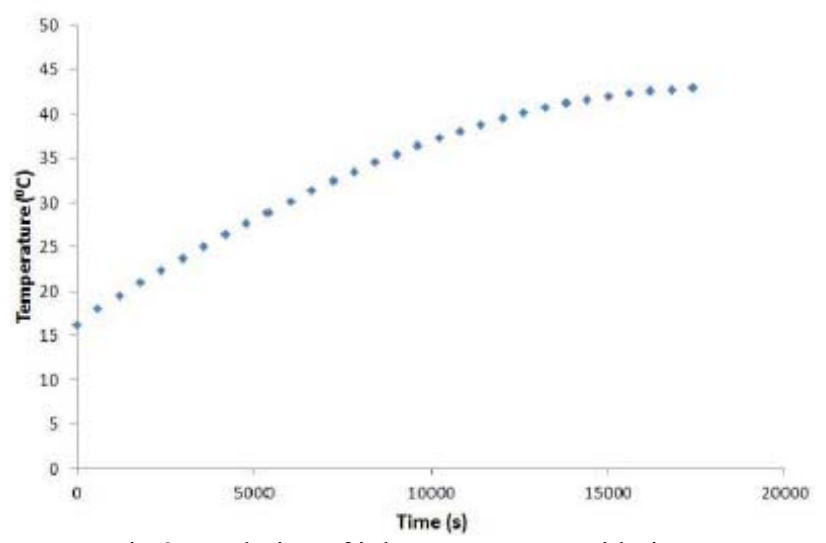

Fig.8: Evolution of inlet temperature with time.

Besides, the inlet velocity is equal to $1.51 \mathrm{~m} / \mathrm{s}$; thus, taking into account the cross-sectional area of the inner 
duct, $1.77 \times 10^{-4} \mathrm{~m}^{2}$, the flow rate is equal to $2.67 \times 10^{-4}$ $\mathrm{m}^{3} / \mathrm{s}$. The inlet temperature $T_{i}$ in (8) is obtained modelling the entire experimental set-up for the prototype collector using COMSOL Multiphysics software and the methodology addressed in [6] where a zero-dimensional (0D) model for a unstratified fully mixed tank is implemented. Initial conditions to carry out the simulation are: $16.7^{\circ} \mathrm{C}$ for temperature and $1.51 \mathrm{~m} / \mathrm{s}$ for velocity. Thermal properties of the transfer fluid are shown in Table II, see [11], where the temperature is expressed in Kelvin.

Table II. - Thermal properties of the heat transfer fluid.

\begin{tabular}{|c||}
\hline$C_{p}$, Specific Heat $(\mathrm{J} / \mathrm{Kg} \mathrm{K})$ \\
$4029.6-3.8886 T+0.0101 T^{2}$ \\
\hline \hline$\mu$, Viscosity $(\mathrm{Kg} / \mathrm{m} \mathrm{s})$ \\
$0.0016(T / 333.15)^{-8}$ \\
\hline \hline$k$, Thermal Conductivity $(\mathrm{W} / \mathrm{m} \mathrm{K})$ \\
$0.3635+2.032 \cdot 10^{-4} T$ \\
\hline$\rho$, Density $\left(\mathrm{kg} / \mathrm{m}^{3}\right)$ \\
$1034.8+0.5317 T-0.0019 T^{2}$ \\
\hline
\end{tabular}

\section{Numerical simulation}

A geometry, created with Gambit 2.4, requiring a cylinder with subtracted inlet and outlet tubes is considered, see Figure 6. Since mesh independence has been assessed using three different meshes as shown in Figure 9; in what follows the mesh depicted in Figure 10 consisting in 405855 hexahedral elements is used.

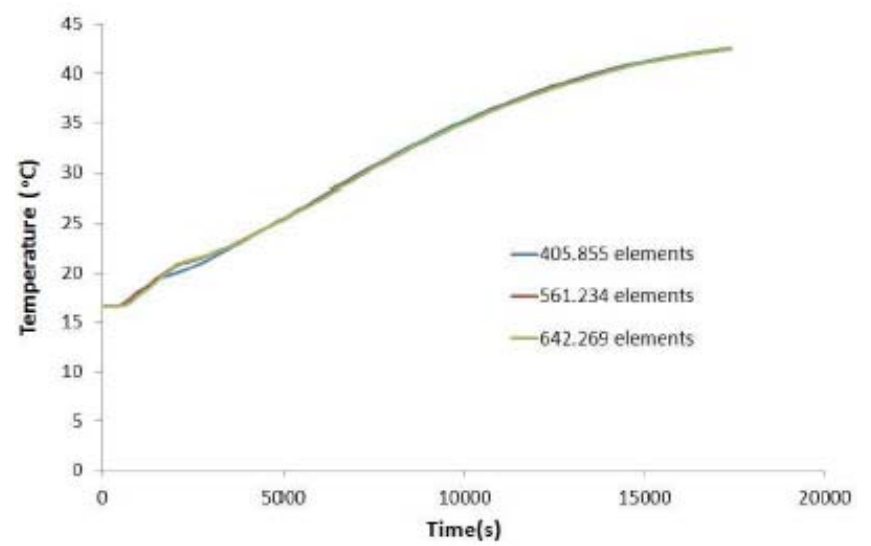

Fig.9: Analysis of the mesh independence.

A numerical simulation has been carried out with Fluent $6: 3$, (see [13]), for an incompressible viscous fluid with given nonlinear density; a standard $k-\varepsilon$ model has also been chosen.

Even though experimental data were taken for a time step of $600 \mathrm{~s}$, (see [8]), we carry out the simulation using a time step of $60 \mathrm{~s}$ for a complete simulation of $17400 \mathrm{~s}$.

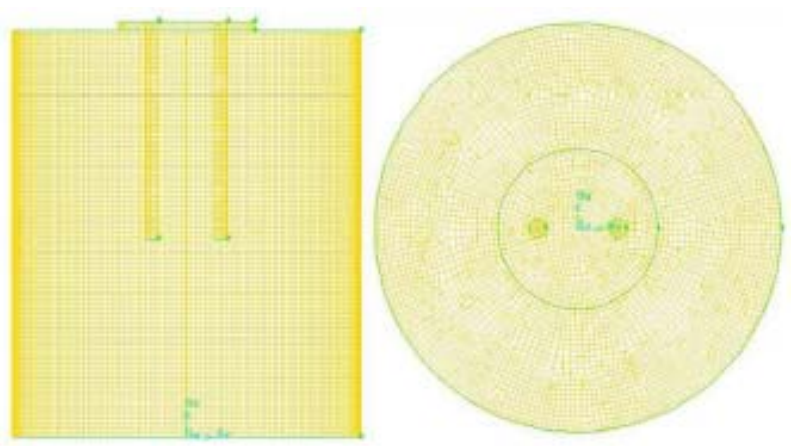

Fig.10: Mesh of the domain.

\subsection{Experimental and numerical results}

In Figure 11, temperature distribution provided by the numerical model at $9000 \mathrm{~s}$ in a vertical plane of the tank is considered. In Figure 12, the temperature distribution at the end of the experiment is shown. It can be seen high uniformity of temperatures in the whole tank, the difference between maximum and minimum temperatures being less than $1.5^{\circ} \mathrm{C}$. In Figures 13 and 14, velocity vectors, colored by their magnitude, are shown at $9000 \mathrm{~s}$ and $17400 \mathrm{~s}$, respectively. As it can be seen, the fluid circulation is important near the inlet duct and it has minor effects at the upper part of the tank.

In Figure 15, the heating curves for the storage tank are presented: the experimental heating curves for the three collectors, BBC, prototype and Roth, are shown as well as the numerical results for both the $0 \mathrm{D}$ - see [8] - and 3D model introduced here. As it can be seen, there is a good agreement between the experimental and numerical results. Noting that the sun exposure area of the prototype is $12 \%$ and $56 \%$ smaller than the $\mathrm{BBC}$ and Roth collectors, respectively, in Figure 16 the energy transferred by each collector to its tank per unit of sun exposure area is shown; it has to be noted the quite good thermal performance of the prototype collector.

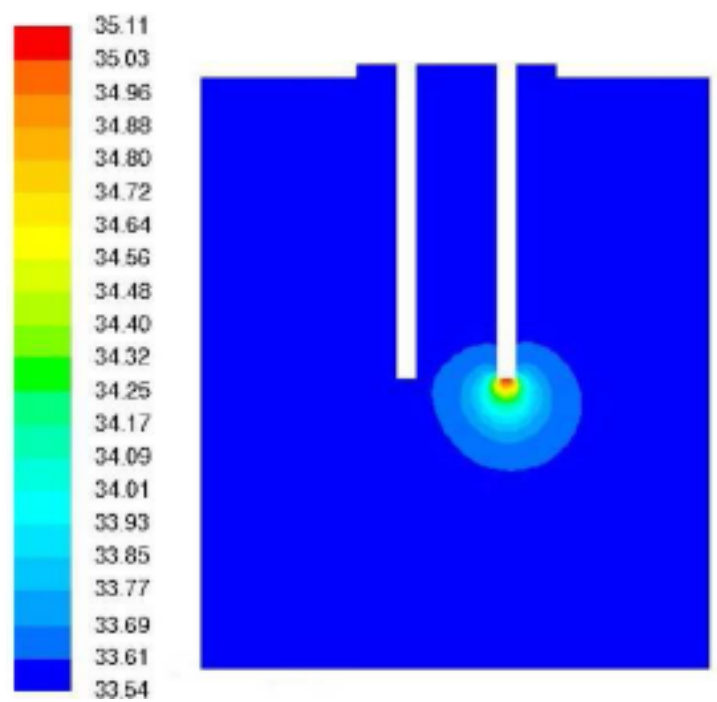

Fig.11: Temperature distribution $\left({ }^{\circ} \mathrm{C}\right)$ at $9000 \mathrm{~s}$. 


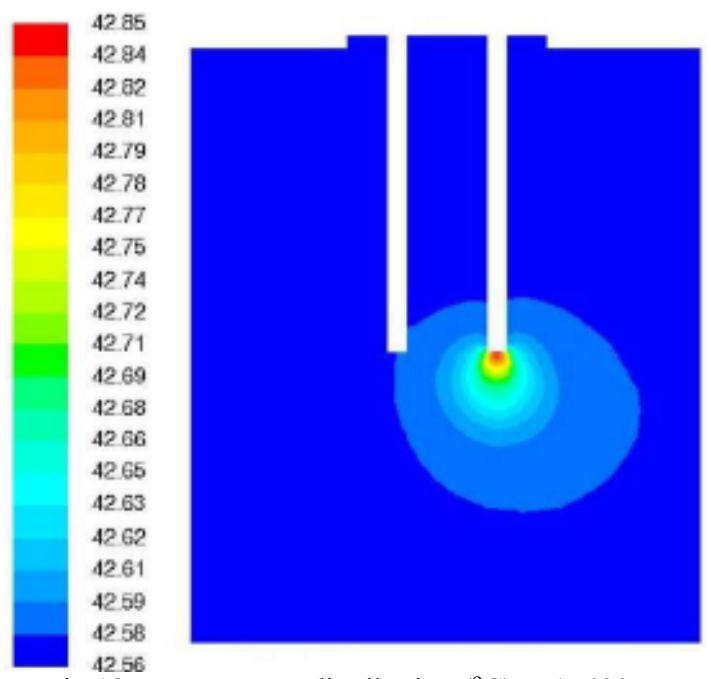

Fig.12: Temperature distribution $\left({ }^{\circ} \mathrm{C}\right)$ at $17400 \mathrm{~s}$.

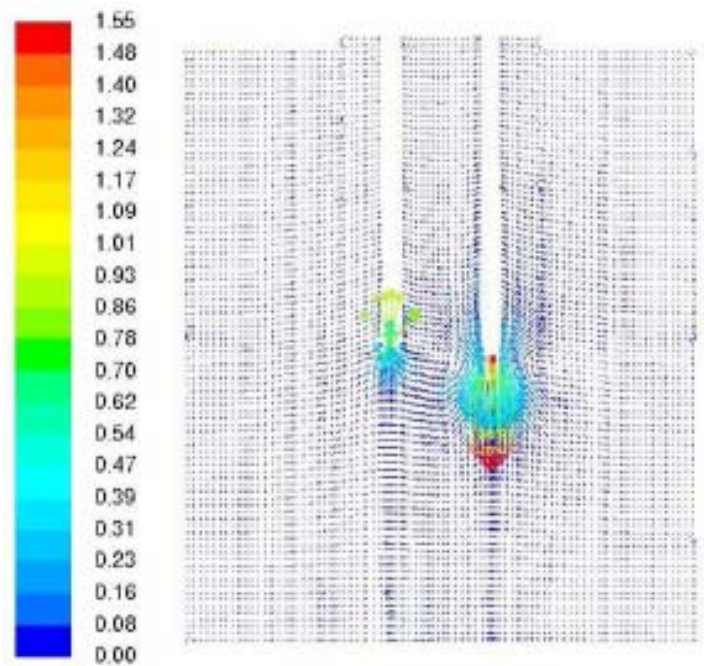

Fig.13: Velocity vectors $(\mathrm{m} / \mathrm{s})$ at $9000 \mathrm{~s}$.

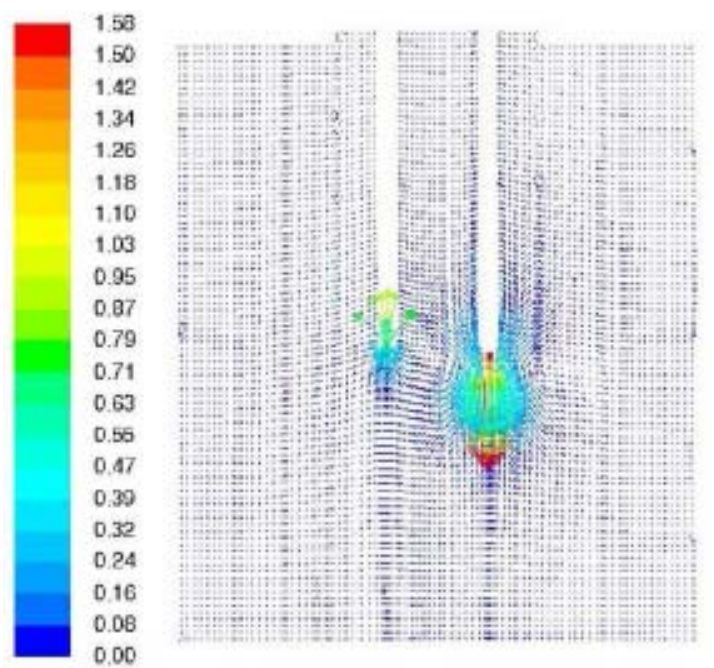

Fig.14: Velocity vectors (m/s) at $17400 \mathrm{~s}$.

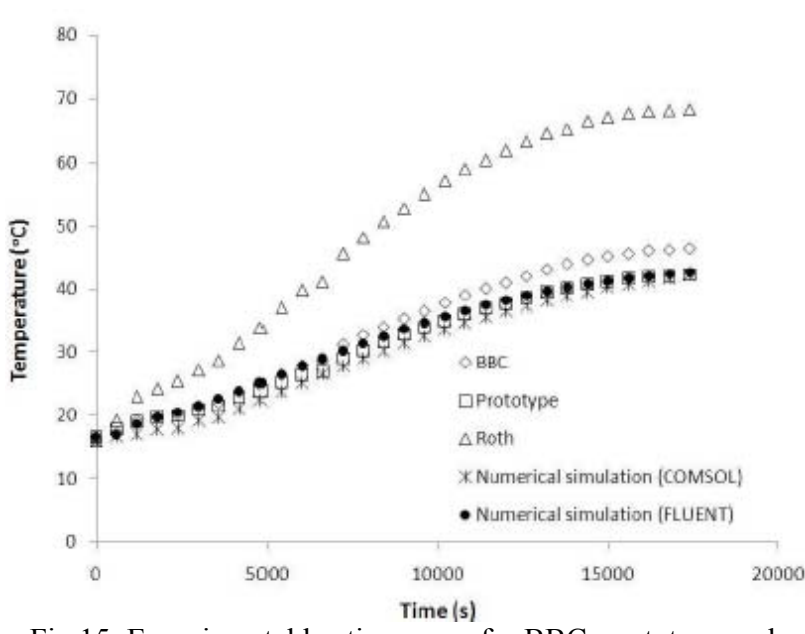

Fig.15: Experimental heating curve for BBC, prototype and Roth collectors together with numerical simulation results.

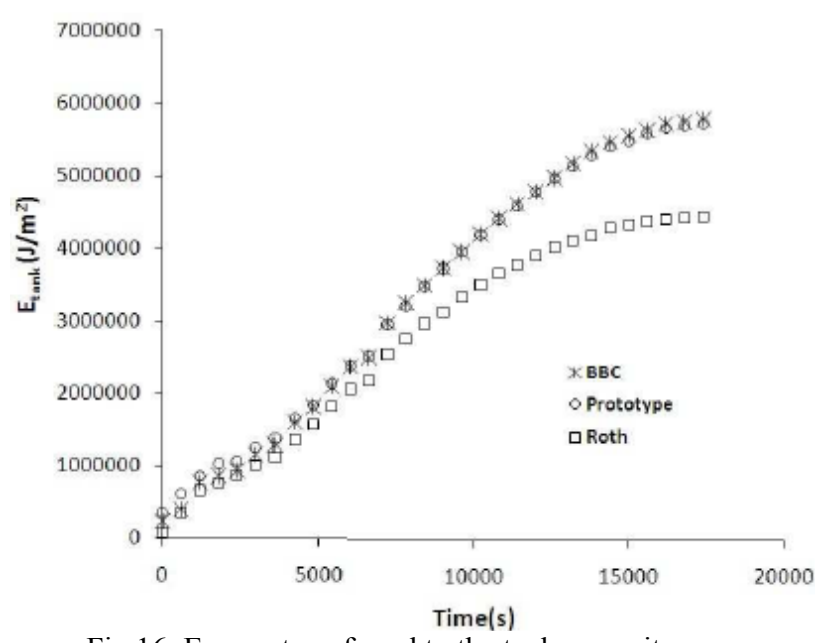

Fig.16: Energy transferred to the tank per unit area.

Finally, surface tank temperatures were recorded by the thermographic camera at $16980 \mathrm{~s}$, see Figure 17, showing values of $42.7{ }^{\circ} \mathrm{C}$ and $42.4{ }^{\circ} \mathrm{C}$ in the vicinity of the inlet and outlet points, respectively. It has to be noted that these data agree with the ones obtained by the 3D numerical model given by $42.705{ }^{\circ} \mathrm{C}$ and $42.414{ }^{\circ} \mathrm{C}$, respectively

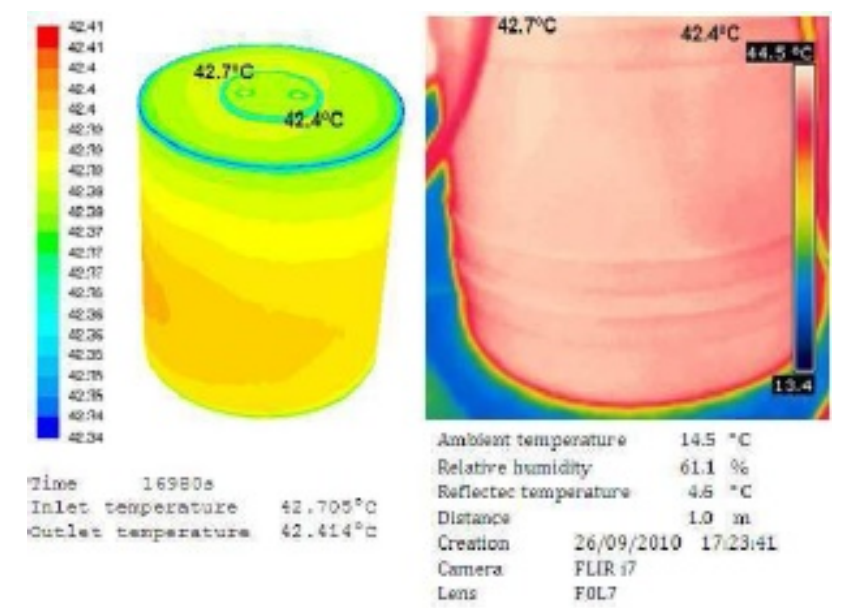

Fig.17: Surface tank temperatures taken by the thermographic camera after $16980 \mathrm{~s}$ of the starting time. 


\section{Conclusions}

In this research, a 3D thermo-hydrodynamic model describing the behaviour of the heat transfer fluid in a storage tank is introduced considering the continuity, momentum and energy equations, complemented with a standard $k-\varepsilon$ turbulence model and using the commercial code Fluent to perform the numerical simulations.

A good agreement of the numerical results compared with experimental measurements for a new flat-plate, sandwichlike solar collector is obtained. The numerical results obtained in this research are also close to the ones obtained with Comsol for a 0D unstratified model of the tank; in fact, as it can be seen high uniformity of temperatures is obtained in the storage tank throughout the computational time that confirms the fact assessed in [14] in terms that thermal stratification decreases as the inlet/outlet distance to the top and bottom of the tank increases.

\section{References}

[1] U. Jordan, S. Furbo, Thermal stratification in small solar domestic storage tanks caused by draw-offs. Solar Energy 78 (2005) 291-300.

[2] S. Furbo, E. Andersen, Performance improvement by discharge from different levels in solar storage tanks. Solar Energy 79 (2005) 431-439.

[3] M.C. Rodriguez-Hidalgo, P.A. Rodriguez-Aumente, A. Lecuona, G.L. Gutierrez-Urueta, R. Ventas, Flat plate thermal solar collector efficiency: Transient behavior under working conditions part II: Model application and design contributions. Applied Thermal Engineering 31 (2011) 2385-2393.

[4] M.C. Rodriguez-Hidalgo, P.A. Rodriguez-Aumente, A. Lecuona, M. Legrand, R. Ventas, Domestic hot water consumption vs. solar thermal energy storage: The optimum size of the storage tank. Appl Energy (2012), doi:10.1016/j.apenergy.2011.12.088.

[5] J.A. Duffie, WA. Beckman, Solar Engineering of thermal processes, $3^{\text {rd }}$ ed. New York, Willey Interscience, 2006.

[6] A. Alvarez, O. Cabeza, M.C. Muñiz, L.M. Varela, Experimental and numerical investigation of a flat-plate solar collector, Energy 35(2010) 3707-3716.

[7] B.E. Launder, D.B. Spalding, The numerical computation of turbulent flows, Comput. Methods Appl. Mech. Eng. 3 (1974) 269-289.

[8] A. Álvarez, Modelado numérico de un colector solar térmico aplicado a buques de crucero y ferrys. Tesis doctoral, Universidad de La Coruña 2011.

[9] http://www.meteogalicia.es

[10] A. Bermudez, Continuum thermomechanics. Progress in Mathematical Physics, 43. Birkhuser Verlag, Basel, 2005.

[11] J. Fan, L.J. Shah, S. Furbo, Flow distribution in a solar collector panel with horizontally inclined absorber strips. Solar Energy 81 (2007) 1501-1511.

[12] J. Welty, Engineering Heat Transfer. John Wiley and Sons, New York, 1978.

[13] Fluent 6.3, User's Guide, September 2006.

[14] S. Ievers, W. Lin, Numerical simulation of threedimensional flow dynamics in a hot water storage tank, Appl Energy 86 (2009), 2604-2614. 